\title{
Linguacultural Features of Teaching English for Specific Purposes in Cross-Cultural Interactions
}

\author{
Marina Krapivina, Vitaly Tomin*, and Natalia Eremina \\ Foreign Languages Department, Orenburg State University, Russia
}

\begin{abstract}
Teaching English for specific purposes to non-linguistic students presents some challenges due to several factors. They are determined by the growing demands of the global economy towards the level of professional competence, diversification of the employers' demands to the employees and the need to account for the cultural peculiarities of regional economies. The authors present a study of organizing the process of English for specific purposes teaching considering linguacultural features. The authors assess the role of English in the modern world and the global economy. English continues to change the language behaviour of people around the globe and is currently the primary tool for large-scale bilingualism. The article analyses the main linguacultural features of different regional business communities' representatives. The article outlines the primary courses design requirements: the communicative orientation and integrating the linguacultural features of professional communication. The authors substantiate the need to develop a methodological, theoretical and practical basis for the implementation of the linguacultural component of the course for the university students.
\end{abstract}

\section{Introduction}

The importance of the international communication in the modern society is directly related to the global issues of developing science, technologies, economies and maintaining reasonable relations and understanding across different cultures. Our society is subject to all kinds of misunderstandings on many levels, from a personal relationship to business and politics.

The goal of linguistic training of university students is to satisfy those social needs that are associated with the active integration of our specialists into world science and professional activities. Success in professional activity on the global market is treated as an achievement of professional goals $[4,6]$. For modern professionals, the ultimate goal of studying a foreign language is "the formation of a linguistic, socioeconomic competence that assumes an adequate use of foreign language code in the implementation of all types of verbal and non-verbal professional intercultural communication in the economic sphere" [4].

The objectives of the University course of foreign language include the development of language, speech, and socio-cultural competence, i.e., mastering the system of a foreign language for scientific and professional communication, proceeding in the cross-cultural interactions with representatives of a different cultural realm [9].

English, as one of the main universally recognized languages of international professional communication, is assumed to ensure the equal access of graduates of
Russian universities to the international professional community. Teaching English for special purposes (ESP) for students of non-linguistic profiles presents some challenges due to several factors. They are determined by the growing demands of the global economy to the level of professional competence of graduates, by the diversification of employers' demands for workers, as well as by the need to consider cultural characteristics of the regional economies.

Apparently, for successful interaction with other people, choosing the appropriate trajectory of relations requires extensive social knowledge. At least, it includes: assessing the situation, assessing the interlocutor, potential relationships with him and his behaviour, strategic planning of the communication style, assimilating the experience of social interaction, social intuition $[2,6]$. Such experience of social and crosscultural interaction can and should be integrated into the process of university teaching English. Also, the main emphasis in such training should be placed on the ability to take into account the linguacultural differences of representatives of different professional and business communities depending on the region.

\section{Theoretical frameworks}

In recent decades, many studies have been carried out that contain ideas about the need of transition to "regional" varieties of the English language. In the methodology of teaching foreign languages, new tendencies have emerged, in which communicative models of language

* Corresponding author: vnimot@yandex.ru 
behavior of communicants are described in terms of their national affiliation (Prokhorov Y.E., Sternin I.A., Turunen N.).

We have considered some recent ideas and investigations that outline the new methodological principles of teaching a foreign language, taking into account the national-specific patterns of trainees' behavior (Chekurieva Y.Y., Furmanova V.P., Kharchenkova L.I., Tomin V.V., Sakharova N.S., Yankina N.V., Kachru Braj B., Chaney L.H., Kleinberg O. and others).

These ideas facilitate the necessity to redeem the contents and the techniques of the ESP teaching course considering linguacultural features and preparing students for the productive cross-cultural interaction.

\section{Materials and Methods}

The research has involved over 800 students of Orenburg State University from humanitarian $(2 \%)$, economical (29\%), juridical (4\%), technical (14\%), automotive $(33 \%)$, and aerospace (18\%) specialties of the full-time department. The representatives of Russia, the CIS, the EU, Northern and Central Africa, and China studying here have participated as the testees to encourage the real-life cross-cultural interaction survey.

The experimental diagnostics of the incoming data included general supervision, different questionnaires, self-analysis essay, CV and professional profile scrutiny.

The forming experiment also induced a somewhat permanent control and feedback employing regular tests (at least, once a week). The latter comprised both students' educational and learning achievements, as well as some complementary external factors, such as psychological stability, social and cultural activity, motivation, interest, tolerance index to different cultures, readiness for cross-cultural interaction.

The resulting data was obtained by similar tests, questionnaires, and interviews. Also, students' final projects (mainly, Microsoft PowerPoint Presentations) helped to gain vital information on the substantial outcomes of the experiment.
The educational process has been organized in the traditional forms: lectures, seminars, practical classes enhanced by the project method and the interactive techniques supplied on the parity basis and following the dialogue principle.

The online interactions have amplified both the students' learning, social and cultural activity, together with the accessibility of its feedback providing valid optional and additional data for a personal multi-sided analysis. The online sessions of teaching English for specific purposes implied the use of Moodle and AIST testing system on www.osu.ru portal along with some specials of Massive Open Online Courses at www.coursera.org.

Some popular social networks (Facebook, Instagram, VK, YouTube, LinkedIn, etc.) with each student's personal permission to include any facts found there into their diachronic profile have complemented to the generalized portrait of every individual involved.

Besides all the empirical methods, only common mathematical ones for processing any data obtained have been used. No previously unknown or author-specific statistics methods have been engaged.

Gender and age variables have demonstrated no significance in cross-cultural interactions, neither in the ESP teaching process and have not been taken into account.

No political, force-major factors or any other impact in a short-time period have been considered or registered in their simultaneous connection or influence on the educational process, and despite any nationality or any side interested and involved.

\section{Results}

Since we accept communication as a central competence in the ESP teaching process, it must be carefully facilitated. More importantly, the process of acquiring communication skills and cultural consciousness should go hand in hand with the basic stages of developing communication skills.

While the current theoretical and practical research

Table 1. Stages of the ESP teaching process.

\begin{tabular}{|l|l|l|l|}
\hline Stages & \multicolumn{3}{|c|}{ Components } \\
\hline Essential & $\begin{array}{l}\text { Cognitive } \\
\text { ability to master the professionally } \\
\text { relevant knowledge, the basic } \\
\text { lexical and grammatical knowledge }\end{array}$ & $\begin{array}{l}\text { Fastering the basic skills of } \\
\text { the linguistic design of } \\
\text { professional non-verbal } \\
\text { communication }\end{array}$ & $\begin{array}{l}\text { formation of the students' value } \\
\text { orientations towards mastering } \\
\text { ESP }\end{array}$ \\
\hline Modelling & $\begin{array}{l}\text { ability to represent an information- } \\
\text { factual aspect of professional } \\
\text { communication by the given } \\
\text { communicative task the }\end{array}$ & $\begin{array}{l}\text { ability to demonstrate the } \\
\text { adequate choice of lexical } \\
\text { means } \\
\text { professional clichés) for } \\
\text { solving communicative tasks }\end{array}$ & $\begin{array}{l}\text { ability to develop a positive } \\
\text { motivation to developing } \\
\text { communicative skills with the } \\
\text { purpose of solving professional } \\
\text { tasks }\end{array}$ \\
\hline Productive & $\begin{array}{l}\text { mastering lexical and grammatical } \\
\text { language means at the level enabling } \\
\text { productive professional activity, } \\
\text { producing speech within a subject }\end{array}$ & $\begin{array}{l}\text { ability for corporate } \\
\text { interaction in the process of } \\
\text { foreign } \\
\text { communication }\end{array}$ & $\begin{array}{l}\text { striving for professional and } \\
\text { communicative mobility in the } \\
\text { process of productive foreign } \\
\text { language communication }\end{array}$ \\
\hline
\end{tabular}


and the experimental arrangement of the teaching process, considering the determined linguacultural features, we have designed the main stages of the ESP teaching process: essential stage, modelling stage, and productive stage.

Each stage includes three main components: cognitive, functional and motivational. The stages of the teaching process are presented in table 1 .

\section{Discussion}

The main components of the ESP course, such as analysing the needs of students and pragmatic focus of the course content, should be adjusted taking into account the cultural characteristics of potential professionals and language users.

According to some authors, correct identification of the students' language needs is a crucial issue in the design of the course and continues to be a professional challenge for ESP teachers around the world. They suggest a flexible approach to the development of the course and the implementation of teaching methodology based on a socio-cultural approach. These conditions can make ESP teaching attractive and practical $[3,7,9,10]$.

The authors dwell that students should gain a deeper understanding of cultural values, corporate culture norms and even professional jargon, which are inherent in representatives of different cultures. They should also consider and master some verbal and non-verbal norms of behaviour, which helps to avoid misunderstandings or even conflict situations associated with critical discrepancies in professional etiquette.

Let's consider the basic requirements, which, in our opinion, are necessary to implement when designing both primary (compulsory) ESP course and additional (optional) language courses for university students. In particular, such courses can be introduced into the optional training program "Interpreter in the professional communication sphere" realized at the Orenburg State University for the students of non-linguistic profiles.

The first requirement for the content of the course is suggested to be the development and intensification of the communicative focus of both content and teaching technologies. Such a requirement results from the need to teach not just language as such, but language as an instrument of communicative activity in conditions of intercultural professional communication. Communication acts both as a training goal and as a means to achieve this goal. Communicative approach implies maximum convergence of the teaching process by its nature with the process of communication. The communicative approach involves the mastery of various speech functions, that is, the ability to express communication intents (request, consent, invitation, refusal, advice, reproach, etc.). This understanding of the communicative approach allowed the researchers (M. Canale, G. Yule, B. Stephen, E. I. Passov, et al.) to describe its main features:

- communication focus of the teaching and learning process realized in various types of speech activity;
- focus not only on the content of communication but also on its forms;

- $\quad$ functionality in the selection and organization of the material: linguistic and speech material should be selected following the functions and communicative intentions of the speaker;

situations as critical forms in the selection of material and organization of training: language and speech material should be selected concerning certain situations of communication and practiced in typical situations as well;

use of authentic materials, which include language forms typical for the expression of a particular communicative intention, authentic texts and communication situations, as well as various verbal and non-verbal means characteristic of native speakers;

- use of genuinely communicative tasks that contribute to the formation of communication skills, and practice format adequate to the conditions of real communication (pair and group work);

- individualization of the teaching process: the use of person-centred approach, that is, considering the students' needs in the planning and organization of classes, reliance on individual cognitive styles and learning strategies, the use of students' personal experience.

Thus, it is evident that the teaching process should be focused mainly on communicative activity, and not on the grammatical component. This does not mean ignoring grammatical accuracy. However, recent studies indicate a tendency to simplifying the grammatical structures used in ESP and the transition to more basic linguistic structures $[3,7,8,11]$.

The next requirement is considering linguacultural features in teaching English for special purposes.

First, it is necessary to consider more deeply the special status of English in the modern world and its unique influence on the global intercultural communication processes. Regarding the population of the Earth, English is superior to the extent of the spread of Latin during the medieval period, to Sanskrit in the ancestral territory of South Asia, as well as to Spanish, Arabic, and French. In other words, English continues to change the linguistic behaviour of people around the globe and is currently the main tool for large-scale bilingualism, since being bilingual now means speaking English as a second language, a language of broader communication, along with one or more of its own languages region. The influence of English penetrates through literary works, international media, cinema and now also through electronic media and the worldwide network. The hegemony of the English language in different countries is manifested in the spheres of business, science, education, management, literature, international communication. However, more importantly, it manifests itself in relation to the English language by its users.

This is the only natural language ever in history, which is spoken as a second (or foreign) language by a significantly bigger number of people than it is spoken by native speakers [13]. It is a high number of the so-called "non-natives" worldwide who now determine the 
processes of spreading and teaching English, its functioning as a universal communication tool. Communicating in English outside the Western countries is mainly communicating with non-native speakers [14].

Thus, the scale of the spread of the English language and its influence on other cultures and languages is a unique phenomenon in history.

Thus, speaking about requirements to the ESP course, we can assume that the integration of knowledge about the language behaviour of non-native language users, in line with the dynamics of the development of language norms inherent in native speakers and their integration into the content of training, guarantees the authenticity of academic requirements for students.

When organizing the educational intercultural communication, it is necessary to consider both the individual cognitive space of the participants and their inner cultural level. It is known that even in case of a common cognitive base and belonging to one nation, misunderstanding can occur because of the divergence of personal cultures.

Intercultural communication can be effectively realized on the levels of the language, culture, and personality of the subjects of communication. The organization of optimal intercultural professional communication in the teaching process implies several preconditions. These include: sufficient knowledge of the national characteristics of representatives of another linguacultural community, the appropriate motivation for communication (the creation of a zone of intersection, the readiness to assimilate the cultural stereotypes of another ethnos or society, expand their cognitive base and perceive the communicative (verbal and nonverbal) behaviour of others). Also, finally, successful intercultural interaction is achieved by the expedient and effective behaviour of communicants who establish and maintain professional communication $[2,11,12]$.

If we consider the essential linguacultural features inherent in business communications among representatives of international business communities, the most distinctive features can be observed in two main categories: cultures based on interpersonal relations (relationship-based cultures) and cultures based on social norms (rule-based cultures). Each type of culture corresponds to its style of communication, in particular, communication in the professional sphere.

Researchers define these styles by these two categories:

1. Relationship-based cultures correspond to highcontext communication style.

2. Rule-based cultures correspond to low-context communication style.

Communicative behaviour in the professional sphere in relationship-based cultures is regulated by the relations "subordinate - superior." Persons of higher rank require explicit (expressive, verbal and nonverbal) linguistic expression of respect. Thus, a natural communicative environment for the expression of interpersonal relations in the professional sphere is formed. It implies implicit norms of communicative behaviour in every professional situation, which tends to a high context of communication $[2,5,6]$.
Communicative behaviour in the professional sphere in rule-based cultures is based on the social norms and the rules that are adopted and implemented by the entire business community. These rules are presented in the explicit form and stand above interpersonal relations, which do not matter for professional contacts. This phenomenon has an impact on the behaviour of communicants, which is more regulated, i.e., tends to low context communication.

According to the materials of the Council of Europe program, the teaching of a foreign language and culture includes training foreign language teachers concerning mastering the necessary repertoire of professional and communicative roles [1]. The latter include such roles as an active, competent and experienced language user; an organizer and active "participant" of educational and communicative events in the classroom, a master instructor, a cooperating partner, an interactive interlocutor, a sympathetic listener, an experienced colleague, a consultant, a source of information and ideas, a researcher, an experienced connoisseur, capable of stimulating language learning and acquiring new cultural and behavioural skills and their effective use.

In fact, the ideas of accounting for linguistic and cultural features can be built into the ESP course program: careful selection of relevant articles from the press, as well as from various business reviews, will provide the necessary basis for the practice of communication and analysis of the situations. Both linguistic and cultural awareness should be built into the communication process in a classroom organized by a competent teacher.

\section{Conclusions}

The ESP course should help students learn both linguistic and cultural features that are reflected in the communicative behaviour of business partners. There already exist both methodological and theoretical developments and sources that provide the necessary information for each stage of mastering competencies within each specific professional situation.

We understand that creating a coherent system of nationally oriented ESP teaching program is still a matter of some perspective. Nevertheless, we hope that the existing theoretical foundations will serve as a basis for continuing scientific research in this field, as well as for the practical use in the compilation of textbooks, teaching manuals and recommendations.

The level of competence for the ESP students may be significantly increased under the condition of creating a nationally oriented language learning paradigm aimed at forming a bicultural identity.

\section{References}

1. C. Leung, J. Lewkowicz, Lang. Educ. 27 (2012)

2. Y. Y. Desherieva, Philology 3 (2000)

3. E. M. Vereshchagin, V. G. Kostomarov, Language and culture. Linguistic country study in teaching Russian as a foreign language (1983) 
4. S. G. Ter-Minasova, Language and Intercultural Communication: Textbook. Benefit (Word, 2000)

5. O. A. Leontovich, Russian and Americans: Paradoxes of Intercultural Communication (2005)

6. E. Kadysheva, Management in Russia and abroad 5 (2006)

7. M. Y. Krapivina, Discussion, 6 (2016)

8. N. S. Sakharova, Bull. of Orenburg St. Univ. 10 (2017)

9. T.S. Bochkareva, Modern researches of social issues 6 (2015)

10. M. Y. Krapivina, Educ. and self-development (2008)

11. L. H. Chaney, J. Martin, Intercultural business communication (2014)
12. O. Kleinberg, Tensions affecting international understanding (1950)

13. B. B. Kachru, ESP in the Classroom. Practice and Evaluation 9 (1988)

14. N. S. Sakharova, V. V. Moroz, N. V. Yankina, E. V. Dmitrieva, ASSEHR, proceedings of the 7th International Scientific and Practical Conference CILDIAH 97, (2017)

15. V. V. Tomin, N. S. Sakharova, N. V. Eremina, O. V. Kabanova, G. V. Terekhova, Global Media J. 1, (2016)

16. N. V. Eremina, Bull. of Orenburg St. Univ. 1 (2016) 